\title{
उMR
}

\section{Trace samples of human blood in mosquitoes as a forensic investigation tool}

\author{
K.C.N. Rabêlo ${ }^{1,4}$, C.M.R. Albuquerque ${ }^{2}$, V.B. Tavares ${ }^{3}$, S.M. Santos ${ }^{4}$, \\ C.A. Souza ${ }^{4}$, T.C. Oliveira ${ }^{1,4}$, N.C.L. Oliveira ${ }^{1}$ and S. Crovella ${ }^{1,5}$ \\ ${ }^{1}$ Laboratório de Imunopatologia Keizo Asami, \\ Universidade Federal de Pernambuco, Recife, PE, Brasil \\ ${ }^{2}$ Departamento de Zoologia, Universidade Federal de Pernambuco, \\ Recife, PE, Brasil \\ ${ }^{3}$ Laboratório de Endemias, \\ Laboratório Central de Saúde Pública de Pernambuco, Recife, PE, Brasil \\ ${ }^{4}$ Laboratório de Perícia e Pesquisa em Genética Forense, \\ Secretaria de Defesa Social de Pernambuco, Recife, PE, Brasil \\ ${ }^{5}$ Departamento de Genética, Universidade Federal de Pernambuco, \\ Recife, PE, Brasil \\ Corresponding author: K.C.N. Rabêlo \\ E-mail: kaynaracecilia@yahoo.com.br
}

Genet. Mol. Res. 14 (4): 14847-14856 (2015)

Received March 17, 2015

Accepted June 9, 2015

Published November 18, 2015

DOI http://dx.doi.org/10.4238/2015.November.18.50

\begin{abstract}
Investigations of any type of crime invariably starts at the crime scene by collecting evidence. Thus, the purpose of this research was to collect and analyze an entomological trace from an environment that is similar to those of indoor crime scenes. Hematophagous mosquitoes were collected from two residential units; saliva of volunteers that were residents in the units was also collected for genetic analysis as reference samples. We examined the allele frequencies of 15 short tandem repeat loci (D8S1179, D21S11, D7S820, CSF1PO, D3S1358, TH01, D13S317, D16S539, D2S1338, D19S433, vWA, TPOX, D18S51, D5S818, and FGA) and amelogenin. A total of 26 female hematophagous mosquitoes were identified as Aedes aegypti,
\end{abstract}


Aedes albopictus, and Culex quinquefasciatus; we were able to obtain 11 forensically valid genetic profiles, with a minimum of 0.028203 $\mathrm{ng} / \mu \mathrm{L}$ of human DNA. Thus, the results of this study showed that it was possible to correlate human genetic information from mosquitoes with the volunteer reference samples, which validates the use of this information as forensic evidence. Furthermore, we observed mixed genetic profiles from one mosquito. Therefore, it is clearly important to collect these insects indoors where crimes were committed, because it may be possible to find intact genetic profiles of suspects in the blood found in the digestive tract of hematophagous mosquitoes for later comparison to identify an offender and/or exclude suspects.

Key words: Mosquitoes blood meal; Forensic DNA; Forensic entomology

\section{INTRODUCTION}

Molecular techniques that profile individuals from a small amount of DNA have facilitated the use of engorged female mosquitoes, which may be crucial for solving some types of crimes. Mosquitoes (Culicidae) are a widely distributed source of human genetic material that can easily be found at crime scenes (Spitarelli, 2006). Genetic profiles obtained from human blood found in the digestive tracts of mosquitoes, for example, can assist in the investigation of crimes committed in a closed environment (such as a room or vehicle; Spitarelli, 2006; Curic, 2014). Comparison of the samples to the suspect's with a DNA database of criminals may also indicate whether a crime is a repeated offense (Wallace et al., 2014).

Intrinsic features of the biology and behavior of mosquitoes are potential advantages to the use of these insects as forensic evidence. Different species are active at different times (morning, twilight, or night) as well as local feeding and resting (indoors, outdoors, and in forests) (Rozendaal, 1997; Mehlhorn, 2008; Takken and Verhulst, 2013). Additionally, their propensity of eating quickly and remaining at the site (Chadee and Beier, 1996, 1997; Edman et al., 1998; Forattini, 2002) allows us to determine DNA profiles from the blood ingested by female mosquitoes, which facilitates identification of people present at the scene or may indicate whether a victim was at the crime scene.

Furthermore, females only stop feeding when the digestive tract is filled with blood, even if they have to feed on more than one host (Canyon et al., 1998; Forattini, 2002). This characteristic is an additional advantage because it can result in more than one human DNA profile (Clayton et al., 1998; Gill et al., 1998; González-Andrade et al., 2006) by female mosquitoes that may have fed on the victim or criminal. Therefore, the links between the suspect, victim, crime, and/or crime scene can be achieved by analyzing mosquitoes (Curic et al., 2014). In this study, we compared the profile of human DNA saliva with blood from the digestive tract of mosquitoes found in the same environment. We also investigated whether multiple feedings of a single mosquito, volunteer sex, and mosquito species would affect the genetic profiles of analyzed blood. 


\section{MATERIAL AND METHODS}

\section{DNA samples obtained from hematophagous mosquitoes}

Hematophagous females were collected from student housing in Recife (Pernambuco, Brazil) called residential units (RUs) "A" and "B." RU "A" is composed of the first floor of a building, and RU " $\mathrm{B}$ " is a one-story house. Both RUs have several rooms and this structure is analogous to common home. Mosquitoes were mainly collected from common areas such as the TV room, study room, bathrooms, and kitchens. The RUs were chosen because we considered them to be similar environments to those in which indoor crimes are committed, and volunteers/residents represented possible suspects.

All mosquitoes found in RUs "A" and "B" were manually captured and placed in plastic pots and then sacrificed with chloroform to aid identification with a stereoscopic microscope (Olympus) using the Consoli and Oliveira (1994) and Forattini (2002) taxonomic keys. After these procedures, the mosquitoes were crushed in filter paper and left to dry for future genetic analysis, which is the same methodology that was followed by Spitaleri et al. (2006).

Research on the biological reference samples was conducted only after authorization of the volunteers; the research was explained and the volunteer signed the informed consent form that gave permission to collect a buccal mucosa sample by wabbing the oral mucosa for further DNA examination (Sweet et al., 1997; Anzai-Kanto et al., 2005). Genetic analyses were performed at Laboratório de Perícia e Pesquisa em Genética Forense (Secretaria de Defesa Social de Pernambuco/Brasil).

\section{Reference samples}

Genetic analysis was performed by comparative study of the alleles found in the electropherograms of volunteer buccal mucosa samples and human DNA found in the blood from the digestive tract of the hematophagous mosquitoes.

\section{Human DNA extraction}

The DNA extraction samples were extracted using the DNA IQ ${ }^{\mathrm{TM}}$ System kit (Promega, Madison, WI, USA) as recommended by the manufacturer.

\section{Genetic analysis}

DNA quantification was performed after DNA extraction with a Quantifiler ${ }^{\circledR}$ Duo DNA Quantification kit (Applied Biosystems, Foster City, CA, USA) using the Real Time PCR ABI 7500 platform. Later, multiplex amplification was performed by PCR analysis using the AMPFlSTR Identifiler Plus ${ }^{\circledR}$ PCR kit (Life Technologies; Carlsbad, CA, USA) following the manufacturer's protocols. Fifteen STR loci were analyzed (D8S1179, D21S11, D7S820, CSF1PO, D3S1358, TH01, D13S317, D16S539, D2S1338, D19S433, vWA, TPOX, D18S51, D5S818, and FGA) in addition to a gender identification marker, amelogenin. PCRs were run for 28 amplification cycles for a total of $2 \mathrm{~h}, 28 \mathrm{~min}$, and $5 \mathrm{~s}$. Blank controls were used to detect possible contamination.

The amplification products were subjected to capillary electrophoresis with the ABI 
PRISM 3500HID automated sequencer (Applied Biosystems, Foster City, CA, USA). Data were analyzed using the GeneMapper ${ }^{\circledR}$ ID-X Software. Non-nucleotide linkers, which are used in primer synthesis for the loci CSF1PO, D13S317, D16S539, D2S1338, and TPOX, allows for simultaneous amplification and efficient separation of the 15 STR loci and amelogenin during automated DNA fragment analysis in accordance with the manufacturer's protocols (Grossman et al., 1994; Baron et al., 1996; Butler, 2005).

The entire protocol followed in this study is the same used by Laboratório de Perícia e Pesquisa em Genética Forense (Secretaria de Defesa Social de Pernambuco/Brasil) in the genetic routine analysis is related to traces of research reports of crime scenes.

\section{Ethics approval}

This study was approved by the Ethics Committee of Universidade Federal de Pernambuco (Recife/Brazil) under protocol No. 462/11.

\section{Statistical analyses}

The likelihood ratio between the questioned sample and the reference was calculated using the PATCAN v.1.2 software (Riancho and Zarrabeitia, 2003) using Bayesian analysis to test the hypothesis that blood found in an entomological trace belonged to a reference sample.

The likelihood ratio (LR) and posterior probability are measures of reliability; consequently, trace criminal evidence can be correlated with references, and the probability can be calculated that a genetic profile would be found in other individual in the population.

\section{RESULTS AND DISCUSSION}

In the present study, a total of 18 biological samples were collected from the oral mucosa of volunteers/residents from RU " $\mathrm{A}$ " $\left(32.5^{\circ} \mathrm{C}, 66 \%\right.$ relative humidity) and nine samples were collected from the oral mucosa of volunteers/residents from RU " $\mathrm{B}$ " $\left(34^{\circ} \mathrm{C}, 56 \%\right.$ relative humidity) for a total of 27 samples references. Twenty-six total female hematophagous mosquitoes (Diptera, Culicidae) were captured; 15 were from RU "A" and 11 were from RU "B." Identification revealed that we collected 13 Aedes aegypti individuals, 12 Culex quiquefasciatus individuals, and one Aedes albopictus individual; the mosquitoes collected from each RU included: seven Ae. aegypti individuals, seven Culex quinquefasciatus individuals, and one Ae. albopictus individual were collected from UR "A", and six Ae. aegypti individuals and five $C x$. quinquefasciatus individuals were collected from UR " $\mathrm{B}$ ". Although it is possible that the DNA will degrade, the consumption of blood by mosquitoes and use of PCR and STR techniques facilitated amplification, enabling interpretation and subsequent validation and confirming the previous results of Alaeddini et al. (2010).

Of the 26 hematophagous mosquitoes, there were 11 samples (Table 1) that would be considered viable trace samples, with amplification of the DNA visualized by the peaks in the electropherograms for profiles of 16 loci (Figure 1). Culicidae mosquitoes, including $A e$. aegypti, Cx. quinquefsaciatus, and/or Ae. albopictus, were used to obtain viable profiles that could be used as a form of evidence for police investigation and judicial proceedings. Even with potentially degraded DNA, it was possible to obtain a number of suitable profiles with electropherogram analysis. 
Table 1. Human DNA amplified from blood in the digestive tract of hematophagous mosquitoes.

\begin{tabular}{|c|c|c|c|c|c|}
\hline $\begin{array}{l}\text { Sample of human } \\
\text { DNA amplified }\end{array}$ & $\begin{array}{l}\text { Sex based on } \\
\text { human DNA profile }\end{array}$ & $\begin{array}{c}\text { Human DNA } \\
\text { quantity }(\mathrm{ng} / \mu \mathrm{L})\end{array}$ & $\begin{array}{c}\text { Prior } \\
\text { probability }(\%)\end{array}$ & $\begin{array}{l}\text { Likelihood } \\
\text { ratio (LR) }\end{array}$ & Posterior probability (\%) \\
\hline Mosquito 1 & Man & 0.041996 & 50 & $3.67 \times 10^{22}$ & 99.99999999999999999999 \\
\hline Mosquito 2 & Man & 0.028203 & 50 & $1.34 \times 10^{21}$ & 99.9999999999999999999 \\
\hline Mosquito 3 & Mixture of two women** & 0.058803 & 50 & $* * *$ & *** \\
\hline Mosquito $4 *$ & Woman* & 0.043155 & 50 & $1.73 \times 10^{25}$ & 99.99999999999999999999999 \\
\hline Mosquito 5 & Woman & 0.109843 & 50 & $2.73 \times 10^{19}$ & 99.99999999999999999 \\
\hline Mosquito 6 & Woman & 0.080513 & 50 & $8.43 \times 10^{18}$ & 99.9999999999999999 \\
\hline Mosquito 7 & Man & 0.042154 & 50 & $5.84 \times 10^{26}$ & 99.999999999999999999999999 \\
\hline Mosquito $8^{*}$ & Woman* & 0.304895 & 50 & $1.73 \times 10^{25}$ & 99.99999999999999999999999 \\
\hline Mosquito $9 *$ & Man* & 0.329996 & 50 & $1.76 \times 10^{20}$ & 99.999999999999999999 \\
\hline Mosquito $10^{*}$ & Man* & 0.133783 & 50 & $1.76 \times 10^{20}$ & 99.999999999999999999 \\
\hline Mosquito 11 & Man & 0.138298 & 50 & $4.92 \times 10^{19}$ & 99.99999999999999999 \\
\hline
\end{tabular}

Bayesian analysis was used for comparisons. ${ }^{*}$ Distinct mosquitoes fed on the same individual; therefore, LR and posterior probability values are equal in the following analyzed mosquitoes: 4 and $8 ; 9$ and 10 . ${ }^{*}$ A single mosquito fed on two female individuals. ${ }^{* * *}$ No comparative statistical analysis because of a lack of reference biological material.
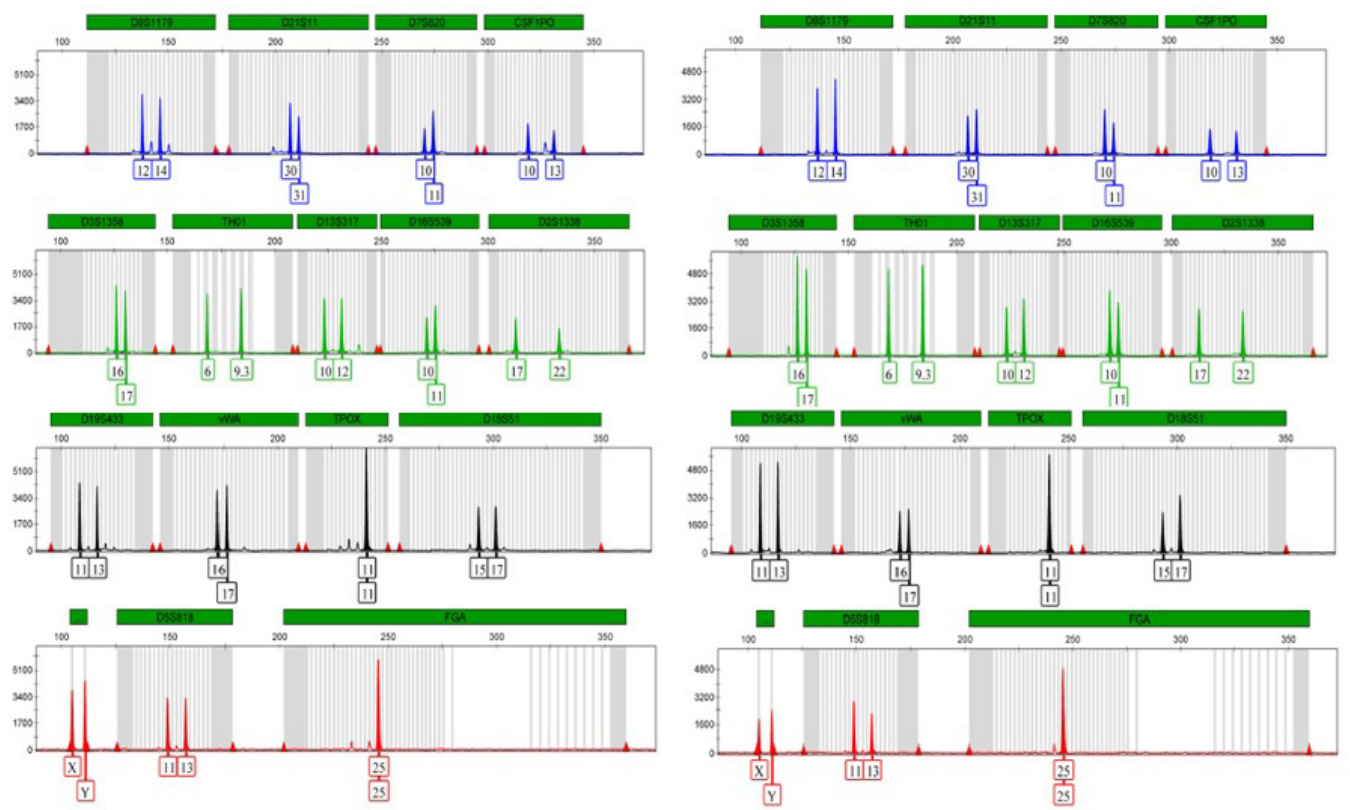

Figure 1. DNA profile of a man. Left, human blood extracted froma Culex quinquefasciatus mosquito; right, reference sample from a volunteer's saliva. Fifteen STR loci and amelogenin were amplified.

Electropherograms for amelogenin revealed five male and five female genetic profiles. In our study, mosquitoes equally preferred biting males and females; this contradicts the reports of Brouwer (1960), Geier et al. (1996), and Brady (1997), who reported that Anopheles stephensi, A. aegypti, and Anopheles gambiae prefer males because of hormonal differences.

This study revealed that even a mixture of human DNA found in a single mosquito could be quantified. Therefore, when a crime occurs, a mosquito may bite the victim and suspect, because sometimes the victim is immobilized and thus would be easier to bite, and the human DNA profile could be accepted as expert proof. 
Human DNA profiles from a single Ae. aegypti mosquito revealed a genetic profile mixture of two women (Figure 2). Additionally, individuals of two different mosquito species (Cx. quinquefasciatus and Ae. aegypti) had blood supplied from a single individual (Figure 3).
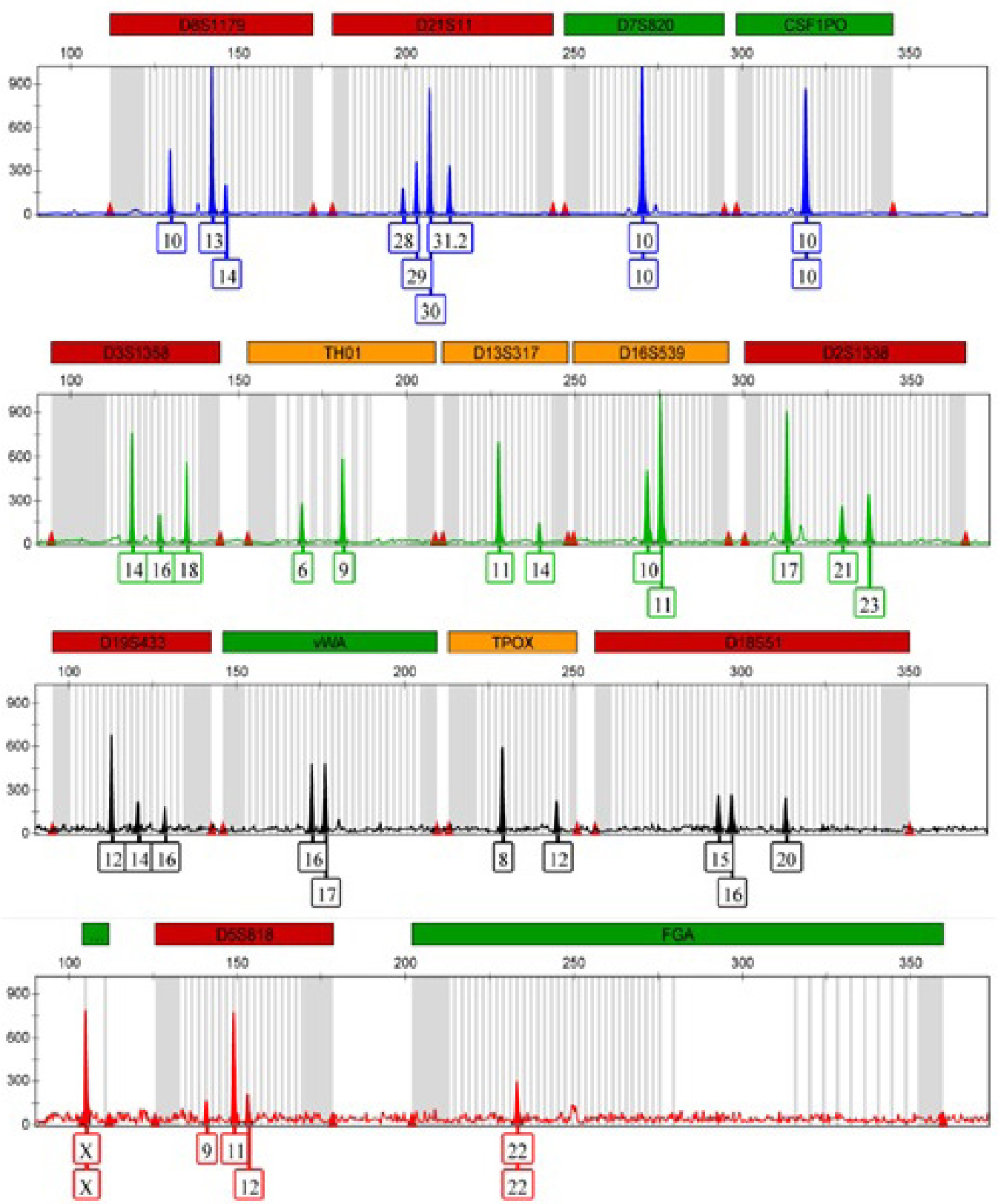

Figure 2. Mixed DNA profiles of two women prepared using human blood extracted from an Aedes aegypti mosquito. Fifteen STR loci and amelogenin were amplified. 

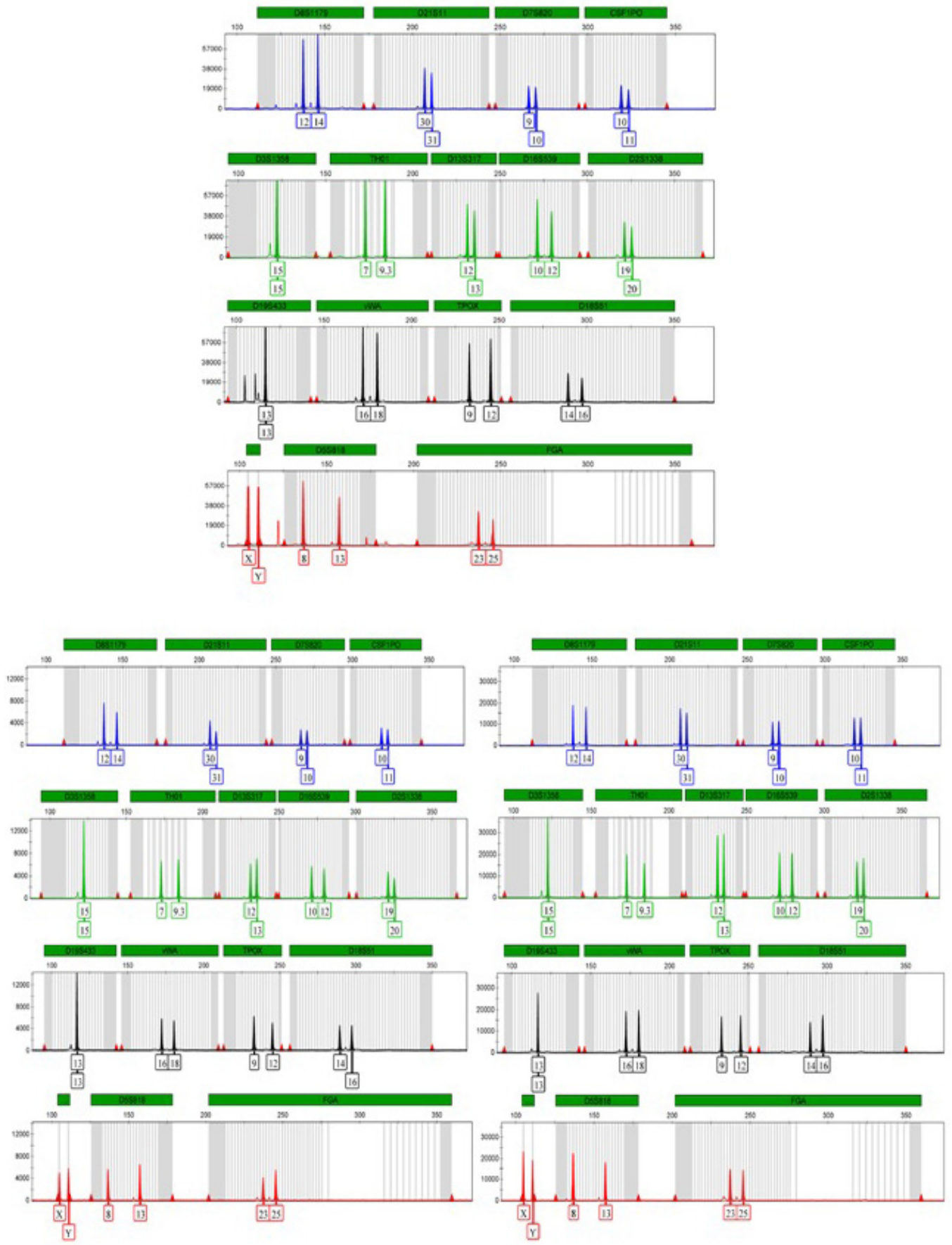

Figure 3. DNA profile of a man whose DNA was detected in blood from two mosquitoes (center, profile of the reference sample; left, profile of human blood extracted from a Culex quinquefasciatus mosquito; and right, profile of human blood extracted from an Aedes aegypti mosquito). Fifteen STR loci and amelogenin were amplified. 
Using 15 STR loci in addition to amelogenin, it was possible to identify the DNA profile of two women in the blood of a female mosquito. The Federal Bureau of Investigation (FBI) recommends a minimum of 13 STR loci for forensic applications (Budowle et al., 1998; Butler, 2005). The authors Haned et al. (2015) reported success in separation and identification of DNA mixture profiles. This type of trace sample has an even greater potential contribution to forensic investigation, because a mosquito could feed on both the victim and offender and both DNA profiles can be analyzed.

DNA extracted from the blood of 11 mosquitoes (Table 1) was amplified and quantified, and the amount of human DNA varied between 0.028203 and $0.329996 \mathrm{ng} / \mu \mathrm{L}$. Mosquitoes 4 and 8 fed on the same woman, and mosquitoes 9 and 10 fed on the same man; however, the quantity of DNA varied among all four mosquitoes (mosquito 4- $0.043155 \mathrm{ng} / \mu \mathrm{L}$; mosquito 8- 0.304895 $\mathrm{ng} / \mu \mathrm{L}$; mosquito 9- $0.329996 \mathrm{ng} / \mu \mathrm{L}$; and mosquito 10- $0.133783 \mathrm{ng} / \mu \mathrm{L}$ ). Mosquito 3, which had a mixture of genetic profiles, had $0.058803 \mathrm{ng} / \mu \mathrm{L}$ human blood and fed on two separate women.

Curic et al. (2014) described the possibility to quantify human DNA in all mosquitoes analyzed, which is an important factor when analyzing mosquitoes as forensic evidence. Genetic analysis revealed that it is possible to identify individuals at a crime scene based on the amount of DNA that can be found in mosquitoes collected from a crime scene, which can help save time and resources.

The lowest value observed was the LR of mosquito 6 with $8.43 \times 10^{18}$; this indicates that the likelihood of the genetic profiles of the reference sample obtained from volunteers and the trace sample of human blood found in the digestive tract of hematophagous mosquitoes at the scene of a crime is at least $8.43 \times 10^{18}$ greater than the chance the DNA came from another person in the population. The posterior probability values were very close to $100 \%$ for all samples.

Genetic analysis and interpretation of this kind of criminal evidence is assisted by statistical analysis using the LR (Weir et al., 1997; Hu et al., 2003; González-Andrade et al., 2006; Primorac and Schanfield, 2014), which is the probability of association between possible trace samples (human blood found in the digestive tract of mosquitoes) and references samples. González-Andrade et al. (2006), who reviewed cases of sex offenders and the resulting mixture genetic profiles, the calculation result of LR was one million, whereas the analysis of human blood hematophagous mosquitoes found in the lowest rate was LR approximately eight quintillion on a population; discriminating enough the association between the possible trace and reference samples. Posterior probability, which indicates the percentage of the genetic profile that would be different in any other individual in the population, the values were all close to $100 \%$ likelihood of the possible trace and reference samples, taking into consideration the hypothesis of this paper it is a similar environment to the site of closed crime.

\section{CONCLUSIONS}

This research confirms that it is possible to analyze human blood found in hematophagous mosquitoes as biological trace evidence and use it as expert evidence. This study revealed that correlation between the reference samples and blood from mosquitoes, regardless of mosquito species analyzed and sex of the individual, can be easily and reliably compared to the obtained laboratory profiles. This facilitates the use mosquitoes as an additional trace for possible biological evidence in closed environments in which crimes were committed. The results of this study also indicate the possibility of identifying DNA profiles from different individuals in the blood mixture of a single female mosquito. 


\section{Conflicts of interest}

\section{The authors declare no conflicts of interest.}

\section{ACKNOWLEDGMENTS}

We thank Laboratório de Imunopatologia Keiso Asami (Recife, PE, Brazil); Andreia da Silva and Vânia Tavares from Laboratório de Endemias/LACEN (Recife, PE, Brazil) for laboratory support; Natália Oliveira for technical support; the volunteers in this study; and members of Laboratório de Perícia e Pesquisa em Genética Forense/Secretaria de Defesa Social (Recife, PE, Brazil) for supporting the genetic analysis.

\section{REFERENCES}

Alaeddini R, Walsh SJ and Abbas A (2010). Forensic implications of genetics analyses from degraded DNA - a review. Forensic Sci. Int: Genet. 4: 148-157.

Anzai-Kanto E, Hirata MH, Hirata RDC, Nunes FD, et al. (2005). DNA extraction from human saliva deposited on skin and its use in forensic identification procedures. Braz. Oral Res. 19: 216-222.

Baron H, Fung S, Aydin A, Bahrig S, et al. (1996). Oligonucleotide ligation assay (OLA) for the diagnosis of familial hypercholesterolemia. Nat. Biotechnol. 14: 1279-1282.

Brady J (1997). The role of body odours in the relative attractiveness of different men to malarial vectors in Burkina Faso. Ann. Trop. Med. Parasitol. 91: 121-122.

Brouwer R (1960). Variations in human body odour as a cause of individual differences of attraction for malaria mosquitoes. Trop. Geogr. Med. 12: 182-196.

Budowle B, Moretti TR, Niezgoda SJ and Brown BL (1998). CODIS and PCR-based short tandem repeat loci: law enforcement tools. In: Proceedings of the second European symposium on human identification, Promega Corporation, Madison, 73-88.

Butler JM (2005). Forensic DNA typing: biology, technology, and genetics of STR markers. Elsevier Academic Press, New York.

Canyon DV, Hii JLK and Muller R (1998). Multiple host-feeding and biting persistence of Aedes aegypti. Ann. Trop. Med. Parasit. 92: 311-316.

Chadee DD and Beier JC (1996). Natural variation in blood-feeding kinetics of four mosquito vectors. J. Vector Ecol. 21: 150-155.

Chadee DD and Beier JC (1997). Factors influencing the duration of blood-feeding by laboratory-reared and wild Aedes aegypti (Diptera: Culicidae) from Trinidad, West Indies. Ann. Trop. Med. Parasitol. 91: 199-207.

Clayton TM, Whitaker JP, Sparkes R and Gill P (1998). Analysis and interpretation of mix forensic stains using DNA STR profiling. Forensic Sci. Int. 91: 55-70.

Consoli RAGB and de Oliveira RL (1994). Principais mosquitos de importância sanitária no Brasil. Editora Fiocruz, Rio de Janeiro.

Curic G, Hercog R, Vrselja Z and Wagner J (2014). Identification of person and quantification of human DNA recovered from mosquitoes (Culicidae). Forensic Sci. Int. Genet. 8: 109-112.

Edman JD, Scott TW, Costero A, Morrison AC, et al. (1998). Aedes aegypti (Diptera: Culicidae) movement influenced by availability of ovipositon sites. J. Med. Entomol. 35: 578-583.

Forattini OP (2002). Culicidologia médica. Editora da Universidade de São Paulo, São Paulo.

Geier M, Sass H and Boeckh J (1996). A search for components in human body odour that attract females of Aedes aegypti (Cardew G and Goode J, eds.). In: Mosquito olfaction and olfactory-mediated mosquito-host interactions, John Wiley \& Sons, New York, 178-183.

Gill P, Sparkes R and Buckleton J (1998). Interpretation of simple mixtures when artefacts such as a stutters are present with special reference to multiplex STRs used by the Forensic Science Service. Forensic Sci. Int. 95: 213-224.

González-Andrade F, Bolea M, Martínez-Jarreta B and Sánchez D (2006). DNA mixtures in forensic casework resolved with autosomic STRs. Int. Congr. Ser. 1288: 580-582.

Grossman PD, Bloch W, Brinson E, Chang CC, et al. (1994). High-density multiplex detection of nucleic acid sequences: oligonucleotide ligation assay and sequence coded separation. Nucleic Acids Res. 22: 4527-4534. 
Haned H, Benschop CCG, Gill PD and Sijen T (2015). Complex DNA mixture analysis in a forensic context: evaluating the probative value using a likelihood ratio model. Forensic Sci. Int. Genet.16:17-25.

Hu Yue-Qing, Fung WK and Lu J (2003). Interpreting DNA mixtures with the presences of relatives. Int. J. Legal. Med. 117: $39-45$.

Mehlhorn H (2008). Encyclopedia of parasitology. Springer, Heidelberg.

Primorac D and Schanfield M (2014). Forensic DNA applications: An interdisciplinary perspective. CRC Press, New York.

Riancho JA and Zarrabeitia MT (2003). PATCAN: a Windows-based software for paternity and sibling analyses. Forensic Sci. Int. 135: 232-234.

Rozendaal JA (1997). Vector control: methods for use by individuals and communities. World Health Organization, England.

Spitaleri S, Romano C, Di Luise E, Ginestra E, et al. (2006). Genotyping of human DNA recovered from mosquitoes found on a crime scene. Int. Cong. Ser. 1288: 574-576.

Sweet D, Lorent M, Lorent JA, Valenzuela A, et al. (1997). An improved method to recover saliva from human skin: the double swab technique. J. Forensic Sci. 42: 320-322.

Takken W and Verhulst NO (2013). Host preferences of blood-feeding mosquitoes. Annu. Rev. Entomol. 58: 433-453.

Wallace HM, Jackson AR, Gruber J and Thibedeau AD (2014). Forensic DNA databases - ethical and legal standards: a global review. Egypt J. Forensic Sci 4: 57-63.

Weir BS, Triggs CM, Starling L, Stowell L, et al. (1997). Interpreting DNA mixtures. J. Forensic Sci. 42: 213-222. 